\title{
Are the last remaining Nassau grouper Epinephelus striatus fisheries sustainable? Status quo in the Bahamas
}

\author{
William W. L. Cheung ${ }^{1,2, *}$, Yvonne Sadovy de Mitcheson ${ }^{2,3}$, Michael T. Braynen ${ }^{4}$, \\ Lester George Gittens ${ }^{4}$
}

\begin{abstract}
${ }^{1}$ Fisheries Centre, AERL, 2202 Main Mall, The University of British Columbia, Vancouver, British Columbia V6T 1E4, Canada ${ }^{2}$ IUCN Groupers and Wrasses Species Survival Commission Specialist Group

${ }^{3}$ Swire Institute of Marine Science, School of Biological Sciences, The University of Hong Kong, Pok Fu Lam Road, Hong Kong SAR ${ }^{4}$ Dept. of Marine Resources, Government of The Bahamas, PO Box N 3028, Nassau, Bahamas
\end{abstract}

\begin{abstract}
Nassau grouper Epinephelus striatus is an important species recreationally, commercially, and for subsistence in the Bahamas. Within most of the species' range, over-exploitation has led to large declines in abundance and to disappearance of spawning aggregations. Nassau grouper is classified as 'Endangered' on the IUCN Red List of Threatened Species. The population(s) in the Bahamas is/are considered to be among the few remaining major Nassau grouper populations globally. However, the recent declining trend in the number of fish landed raises concerns about the sustainability of the Bahamas' population(s). In this study, we provide an appraisal of the current status of the fisheries and explore the potential effects of different fishery and conservation management scenarios on the Nassau grouper population and the fisheries. The study uses existing biological and fishery data together with fishers' knowledge on fisheries collated from an interview survey. The results suggest that the population is now fully- to over-exploited and under decline, although this needs to be validated when more fishery and population data have been collected and analyzed. A precautionary approach to managing the Bahamas' Nassau grouper is to maintain spawning aggregation closures, and to improve the monitoring, control, and surveillance to address poaching. Also, fishing mortality rates should be reduced to below the 1998-2001 level during non-spawning aggregation periods. These measures will increase spawning potential and maximize the long-term economic benefits of the fisheries. Other potential threats to the Nassau grouper population, such as the invasion of lionfish, increased use of compressors, and the taking of immature fish, should be monitored and assessed.
\end{abstract}

KEY WORDS: Nassau grouper $\cdot$ Fisheries $\cdot$ Bahamas $\cdot$ Spawning aggregation $\cdot$ Closure $\cdot$ Stock assessment

Resale or republication not permitted without written consent of the publisher

\section{INTRODUCTION}

Over-exploitation has led to large declines in the abundance of most Nassau grouper Epinephelus striatus populations globally (Cornish \& Eklund 2003). The Nassau grouper has been reported from Bermuda, Florida (USA), the Bahamas, the Yucatán Peninsula (Mexico), and throughout the Caribbean (Froese \& Pauly 2011), although its occurrence in
Brazil is unconfirmed (Cornish \& Eklund 2003). It is particularly vulnerable to over-exploitation because of its life history characteristics, such as large body size (asymptotic length $>90 \mathrm{~cm} \mathrm{TL}$ ) and long lifespan (estimated longevity of $30 \mathrm{yr}$ or more), and because it spawns in aggregations at specific times and locations (Cheung et al. 2005, Reynolds et al. 2005, Sadovy de Mitcheson et al. 2008). The latter characteristic makes Nassau grouper, particularly the 
spawning adults, an easy and highly predictable target for fisheries (Sadovy \& Domeier 2005). Declines in landings and catch per unit effort (CPUE) have been reported throughout its range, and the species is now considered to be commercially insignificant in most areas (Sadovy \& Eklund 1999). Many of its spawning aggregations are now thought to have been extirpated (Sadovy de Mitcheson et al. 2008). Nassau grouper is classified as 'Endangered' with a decreasing trend on the IUCN Red List of Endangered Species (www.redlist.org) due mainly to the unregulated fishing of spawning aggregations.

The Bahamas is among the few remaining areas where substantial catches of Nassau grouper are reported. Nassau grouper has long been an important species that contributes considerably to the diet of people in the Bahamas and is an important species for commercial and recreational fishing. In 2011, according to official landings statistics from the Bahamas' Department of Marine Resources (unpublished data), total commercial landings of Nassau grouper amounted to $113 \mathrm{t}$, contributing approximately \$US 855700 in landed value. In the Bahamas, Nassau grouper is fished commercially and recreationally by handline, longline, fish traps and pots, spear guns, and gillnets, although data on the recreational and subsistence fisheries are lacking.

In the Bahamas, assessment of the population status of Nassau grouper in 1998 to 2001 suggested that fishery exploitation rates in this period ranged from 0.25 to 0.38 (Ehrhardt \& Deleveaux 2007), with fishing mortalities considerably lower than in other populations in the Caribbean for which information was available. A fishing ban on spawning aggregations has been variously implemented since 1998, although the extent of enforcement and effectiveness of the ban have not been studied, and poaching is known to occur. Since the Nassau grouper in the Bahamas is amongst the last few remaining substantial populations of this Endangered species globally, under- standing its population status and the effectiveness of existing fishery management is important for the conservation of this species as well as the viability of the fishery. In this paper, although we use the singular form 'population' when we refer to the Nassau grouper population(s) in the Bahamas, the species' population structure is unknown; nor is it known whether the species consists of a single or multiple population(s) in the Bahamas.

Here we aim to provide an appraisal of the current status of the Nassau grouper fisheries in the Bahamas. We explore the potential effects of different fishery and conservation management scenarios on the Nassau grouper population and associated fisheries. The study combines available biological and commercial fishery data with fishers' knowledge on fisheries collated from an extensive interview survey to better understand the status of Nassau grouper fisheries. Moreover, a population dynamic model is used to explore the consequences of different levels of fishing and spawning aggregation protection for the future status of the Nassau grouper population and fisheries. Based on results from different sources and analyses, we identify the current status and trends of the Nassau grouper population and fisheries, discuss implications for fishery and conservation management, and address the main information gaps and uncertainties.

\section{MATERIALS AND METHODS}

\section{Data sources}

We collated available data on the biology, population, and fisheries of the Bahamas' Nassau grouper (Table 1). Basic biological information was based largely on a comprehensive review by Sadovy \& Eklund (1999), a recent stock assessment conducted by Ehrhardt \& Deleveaux (2007), and unpublished infor-

Table 1. Epinephelus striatus. Sources of data used in the assessment of the Bahamas' Nassau grouper. CPUE: catch per unit effort

\begin{tabular}{|c|c|c|c|}
\hline Data & Period & Analysis & Source \\
\hline Landings & 1994-2011 & Overall trend indicates fishery production & Bahamas' Department of Fisheries ${ }^{a}$ \\
\hline Landings-at-age & 1998-2001 & Catch curves to estimate total mortality rates & Ehrhardt \& Deleveaux (2007) \\
\hline CPUE & 1999-2004 & Overall trend indicates relative abundance & Bahamas' Department of Fisheries \\
\hline $\begin{array}{l}\text { Survey (interviews } \\
\text { of fishers) }\end{array}$ & 2001 & $\begin{array}{l}\text { Fishers' perception on changes in fishery } \\
\text { production, CPUE, management effectiveness, } \\
\text { and stock status }\end{array}$ & Bahamas' Department of Fisheries \\
\hline
\end{tabular}


mation on landings made available by the Bahamas Fishery Department (see Fig. 1). Data on landings and landed values from 1994 to 2009 were compiled from the Bahamas' Department of Marine Resources statistics. Also, catch (landings)-at-size data from 1998 to 2001, used in the stock assessment of Ehrhardt \& Deleveaux (2007), were obtained to re-estimate exploitation rates, fishing mortality, selectivity, and abundance of the Bahamas' Nassau grouper during that period. However, landings data (without effort information) only indicate the level of fisheries production, while survey and assessment data are only sporadically available, rendering direct estimation of abundance trends, which requires CPUE, impossible. In addition, and for the purposes of the current study, 280 Bahamas' fishers were interviewed with a structured questionnaire to collate fishers' experiences and views on the status of the Nassau grouper fishery and their concerns regarding its future (Bahamas Dept. of Marine Resources unpublished data). A further 32 detailed interviews were conducted in 2010 to collect additional economic and fisheries-related information (Bahamas Dept. of Marine Resources unpublished data). Most of the interviewed fishers were engaged in full-time fishing and had over $15 \mathrm{yr}$ of fishing experience. Furthermore, daily catch and effort data from 1999 to 2004 were obtained from the Department of Marine Resources of the Bahamas government.

\section{Analysis of CPUE data}

We used a generalized linear model (GLM) to analyze the CPUE data obtained from the Bahamas' Department of Marine Resources and to evaluate any effects of fishing gear, year, month, and fishing ground on CPUE of Nassau grouper (Table S1 in the supplement at www.int-res.com/articles/suppl/n020 p027_supp.pdf). The dataset contains catch and effort (expressed as number of boats $\times$ fishers $\times$ fishing days) by year (from 1999 to 2004), month, fishing gear, and fishing ground. We used a GLM to standardize the reported CPUE across fishing gears, fishing grounds, year, and month of fishing and to identify any significant annual and seasonal trends in CPUE over this period (Cheung \& Pitcher 2008). Because of the distribution structure of the CPUE data, we assumed that CPUE was log-normally distributed. Thus,

$$
\begin{aligned}
\log (\mathrm{CPUE})= & a \times \mathrm{Year}_{n}+b \times \mathrm{Month}_{m} \\
& +c \times \mathrm{Gear}_{y}+d \times \mathrm{FG}_{z}+\varepsilon
\end{aligned}
$$

where $a, b, c, d$ are coefficients for the factors of $n$ year of fishing (Year), $m$ month of fishing (Month), $y$ type of fishing gear (Gear) and $z$ different fishing ground (FG). $\varepsilon$ is the error term. Because of the limited sample size, we did not test for interactions between factors.

\section{Estimating exploitation rates and gear selectivity}

We used the dataset from Ehrhardt \& Deleveaux (2007) to estimate exploitation rate and selectivity. Following their method, the landings-at-length data were fitted with length-based catch curves (Jones 1984) to estimate the total mortality rate, in which:

$$
\begin{gathered}
\frac{N_{l}}{\Delta t}=\partial+Z \times \alpha_{1} \\
\Delta t=\frac{1}{K} \log _{\mathrm{e}} \frac{\left(L_{\infty}-1\right)}{\left(L_{\infty}-l^{\prime}\right)} \\
\alpha=\frac{\log _{\mathrm{e}}\left(1-\frac{\bar{l}}{L_{\infty}}\right)}{-K}
\end{gathered}
$$

where $N_{l}$ is the number of fish at length-class $1, Z$ is the total mortality, $\partial$ is the intercept of the linear regression between $N_{l} / \Delta t$ and $\alpha, \alpha$ is the age of that particular length class, $K$ is the von Bertalanffy growth parameter, $\Delta t$ is the average time that the fish spends growing from the lower $\left(l^{\prime}\right)$ to the upper size limits $(l)$, $\bar{l}$ is the median size of the length class, and $L_{\infty}$ is the asymptotic length and growth parameter of the von Bertalanffy growth function.

Following the analytical methods of Ehrhardt \& Deleveaux (2007), length-based virtual population analysis (VPA; Jones 1984) was used to estimate fishing mortality rates, selectivity, and abundance-atlength classes. The estimated parameters were then used in the stock assessment model.

\section{Stock assessment model}

The biological reference points indicating fisheries status were estimated based on a stock assessment approach for data-poor fisheries documented by Sadovy et al. (2007). The basic population dynamic model is based on an age-, sex-, and size-structured model. The model also assumes that fishing and natural mortality occur throughout the year. Sex change from female to male is assumed to be negligible, with a probability of 0.001 for individuals between the length of 15 to $60 \mathrm{~cm}$ (based on data from Sadovy \& 
Colin 1995 and Sadovy \& Eklund 1999). Recruitment of age- 0 animals is assumed to be density dependent and follows a Beverton-Holt function (Hilborn \& Walters 1992), and recruitment was expressed as a function of the gonad weight of mature females. Because of the lack of information on the impact of sex ratio on recruitment, and since there is no a priori reason to expect such an effect in this species, we did not consider the potential impact of changes in sex ratio; indeed, fishing does not appear to have marked effects on adult sex ratio in this species (Sadovy \& Eklund 1999). The model considers that the Bahamas' Nassau grouper is a single population, although this may not reflect the real population structure, particularly as coral reef fishes tend to form meta-populations (Bay et al. 2008).

In the model, all sexually mature individuals spent $2 \mathrm{mo} \mathrm{yr}^{-1}$ in spawning aggregations, with independent fishing mortality between non-spawning and spawning groups. We assumed that spawning aggregation fishing targets adult fish only because immature fish are assumed not to form aggregations. However, there is some indication that immature-sized fish occasionally occur at aggregation sites, possibly learning the site location from adults (Y. Sadovy de Mitcheson unpubl. data). Thus, this assumption may render the estimates of fishing effects on the fish population more conservative because we may underestimate fishing mortality of immature fish during the spawning aggregation. Catchability in spawning aggregations should be higher than during the non-spawning period (Sadovy \& Eklund 1999). Direct estimation of the difference in catchability is lacking; thus we approximated this difference using information obtained from fisher interviews (Table 1). Fishers in the Bahamas were asked about the average CPUE (number of fish per person per fishing day) during spawning and non-spawning periods. A total of 22 fishers provided estimates for the 2 periods. We then calculated the ratio of CPUE between spawning and non-spawning periods; the result gave a median of 6.4:1, and 10th and 90th percentiles of 3.1:1 and 12.9:1. To accommodate this uncertainty, we set this factor as a uniform probability distribution that ranges from 3.1:1 to $12.9: 1$ as levels of catchability during non-spawning periods.

The mathematical form of the model is:

$$
N_{a+1, s, l}=\sum_{l}^{1} X_{S_{1} l^{\prime}, l} \times N_{a_{1}, l^{\prime}} \times \mathrm{e}^{-\left(m+F_{1} \times p_{l^{\prime}}+F_{2} \times p_{I^{\prime}}-\text { mat }_{l^{\prime}}\right)}
$$

where $N_{a, s, l}$ is the number of fish at age $a, s$ is sex (male or female), $l$ is length class, and $p_{1}$ is the fishery selectivity (proportion of population that is fully vul- nerable to fishing) at size $1 . X$ is the probability of fish growing from size $l^{\prime}$ to $l . F_{1}$ and $F_{2}$ are fishing mortality rates for non-spawning and spawning aggregations, respectively, and mat $_{\mathrm{l}^{\prime}}$ is the proportion of females matured at length 1 . Selectivity $p$ was estimated from the length-based VPA analysis and assumed to be constant over time.

Catch $(C)$ is calculated from:

$$
C=R \times \sum_{a} \sum_{l} N_{a_{1} l} \times \frac{p \times\left(F_{1}+F_{2}\right)}{M+p_{1} \times\left(F_{1}+F_{2}\right)} \times\left[1-\mathrm{e}^{-\left(M+p_{1}\right)}\right]
$$

where $M$ is natural mortality rate and $R$ is recruitment to age-0 groups, which is calculated from:

$$
R=\frac{4 h R_{0} E}{R_{0} \bar{E}_{0}(1-h)+(5 h-1) E}
$$

where $R_{0}$ is the unexploited number of $0 \mathrm{yr}$ olds, $h$ is the steepness parameter, and $E$ is the gonad weight of ripe females, calculated from:

$$
E=\sum_{a} \sum_{l} N_{a, l} \mathrm{~g}_{l} \mathrm{mat}_{l}
$$

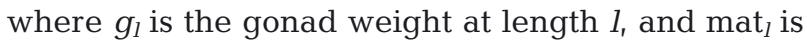
the proportion of females that matured at length 1 . $\overline{\mathrm{E}}_{0}$ is the gonad weight of ripe females-per-recruit in the absence of exploitation. $h$ was calculated from a Bayesian hierarchical meta-analysis for steepness parameters of 12 coral reef-associated fishes as documented by Sadovy et al. (2007).

Growth was modeled using the von Bertalanffy growth function:

$$
\begin{gathered}
L_{a}=L_{\infty} \times\left(1-\mathrm{e}^{-K\left(a-t_{0}\right)}\right) \\
W_{a}=x \times L_{a}^{y}
\end{gathered}
$$

where $L_{\infty}$ is the asymptotic length, $K$ is the growth parameter, $t_{0}$ is the theoretical age when body size is zero, $W_{a}$ is body weight at age $a$, and $x$ and $y$ are the length-weight conversion parameters (Table 2).

Equilibrium catch and spawning potential (spawner abundance or biomass relative to unexploited levels) were calculated at different levels of fishing mortality using the population dynamic model described above. We expressed fishing mortality as the percent difference from the average fishing mortality rate in 1998 to 2001 . We estimated the fishing mortality rate that would result in a spawning potential of $35 \%$ relative to the unexploited level $\left(F_{\mathrm{SPR}=35 \%}\right)$, which is commonly used in fisheries stock assessment. Although a more liberal reference point of $F_{\mathrm{SPR}=20 \%}$ (i.e. fishing mortality rate that would result in a spawning potential of $20 \%$ ) has been used in some cases (Sadovy et al. 2007), the same study also noted that a reduction of spawning potential to $20 \%$ of the unexploited level 
Table 2. Epinephelus striatus. Published and estimated parameter values relating to life history of Nassau grouper used in the population dynamics in this study. BW: body weight (g), TL: total length (cm), GW: gonad weight to body weight relationship. The ratio of catchability was estimated based on information from 22 interviewed fishers, who were asked about the average catch per unit effort (CPUE: number of fish per person per fishing day) during spawning and non-spawning periods. We then calculated the ratio of CPUE from spawning to non-spawning periods, which has a median of 6.4:1, and 10th and 90th percentiles of $3.1: 1$ and 12.9:1

\begin{tabular}{|c|c|c|}
\hline Parameter & Values & $\begin{array}{l}\text { Assumed distribution in } \\
\text { Monte Carlo simulation }\end{array}$ \\
\hline Asymptotic length $\left(L_{\infty}\right)^{\mathrm{a}, \mathrm{b}}$ & $70-97.4 \mathrm{~cm}$ & Uniform \\
\hline von Bertalanffy growth parameter $(K)^{\mathrm{a}, \mathrm{b}}$ & $0.063-0.185 \mathrm{yr}^{-1}$ & Uniform \\
\hline Variance of growth ${ }^{a, c}$ & 9 & - \\
\hline Natural mortality rate $(M)^{\mathrm{a}, \mathrm{b}}$ & $0.17-0.4 \mathrm{yr}^{-1}$ & Uniform \\
\hline Rate of sex change from female to male $\mathrm{a}^{\mathrm{a}, \mathrm{d}}$ & $0.001-0.05$ & Uniform \\
\hline Length-weight relationship ${ }^{a}$ & $\mathrm{BW}=0.010578 \times \mathrm{TL}^{3.277}$ & - \\
\hline Recruitment steepness parameter ${ }^{\mathrm{e}}$ & Mean $=0.898 ; \mathrm{SD}=0.912$ & $\begin{array}{l}\text { Logit of steepness is assumed } \\
\text { to be normally distributed }\end{array}$ \\
\hline Gonad to body weight relationship ${ }^{a}$ & $\mathrm{GW}=[(\mathrm{BW}-0.187) / 1.275]-0.219-0.535$ & - \\
\hline $\begin{array}{l}\text { Ratio of catchability of fishing in spawning } \\
\text { period relative to non-spawning period }\end{array}$ & $3.1: 1-12.9: 1$ & Uniform \\
\hline
\end{tabular}

may considerably affect recruitment. Since Nassau grouper reproduces through the formation of spawning aggregations, the population may be more vulnerable to any depensatory effects of low population size on reproduction. There are many examples whereby large reduction in spawner abundance of Nassau grouper led to apparent disappearances of spawning aggregations, e.g. one-third of the Nassau grouper spawning aggregations in Belize have disappeared due to overfishing (Sala et al. 2001), and throughout the species' range, many aggregations evidently no longer form (Sadovy de Mitcheson et al. 2008). Thus, this provides justification for the use of a more conservative reference point of $F_{\mathrm{SPR}=35 \% \text {. In }}$ addition, the fishing mortality rates for achieving long-term equilibrium maximum sustainable yield $\left(F_{\mathrm{MSY}}\right)$ were estimated.

A Monte Carlo simulation was undertaken in which parameter values for the stock-recruitment steepness, and the increase in catchability when Nassau grouper is in spawning aggregation, were drawn from a pre-defined probability distribution (see Table 1). Fishing mortality rates for Nassau grouper at non-spawning aggregations $\left(F_{1}\right)$ and spawning aggregations $\left(F_{2}\right)$ were varied from 0 to 2 times the current fishing mortality rate. For each combination of $F$ values, Monte Carlo simulation of 200 runs was undertaken, and the median and 95\% confidence intervals for catch and spawning potential were calculated.
A simple bioeconomic analysis was conducted to explore the effects of different scenarios of fishing mortality in non-spawning and spawning periods on economic rent of the Bahamas' Nassau grouper fisheries. First, based on the fisher interviews (see next sub-section), we estimated the average price of Nassau grouper in the Bahamas in the 2000s period. Also, we obtained estimates of fixed (interest and depreciation) and variable (fuel, repair, labor) costs from the Global Ocean Economic project fishing cost database (Lam et al. 2011). We calculated the economic rent as:

Rent $=$ Price $\times C-$ Variable cost $\times f-$ fixed cost (11) where $C$ is catch calculated from the population dynamic model under a fishing mortality of $F$. We assume that fishing effort $f$ is directly proportional to $F$. We then calculate the fishing mortality to achieve equilibrium maximum economic rent (MER), or $F_{\mathrm{MER}}$.

\section{Analysis of data from the interview survey}

Information from an interview survey with 280 Bahamas' fishers conducted by the Bahamas Department of Marine Resource in 2010 was analyzed (Department of Marine Resources, Government of the Bahamas unpublished data). The survey focused strongly on soliciting information and views in relation to the spawning aggregation closures initially 
implemented in the late 1990s. Fishers' information and views on the economic importance of the Nassau grouper fishery to their livelihood, and the trends of the fishery and population, before and after the spawning recruitment closure, were collated. Also, in an additional set of 32 interviews, fishers were asked about the price of Nassau grouper catch and their concerns on the future of the Nassau grouper fishery. This information was used to supplement results from the stock assessment to develop a more comprehensive understanding of the status and trends of the Nassau grouper population and fisheries.

Descriptive statistics were presented in most cases except in the analysis of fishers' experience on previous catches of Nassau grouper from spawning aggregations. In the latter case, specifically, we investigated the changes in the largest catch from spawning aggregations that the fisher had ever had in different periods of the past because this indicates a 'shifting baseline' of fishers' understanding of the abundance and productivity of the resources over time (SáenzArroyo et al. 2005), and, moreover, fishers are more likely to remember their largest rather than their average catches; the occurrence of a 'shifting baseline' towards less abundant and productive fish populations is an indication of degradation of the resources (Pauly 1995, Jackson et al. 2001). We calculated the CPUE, expressed as weight of fish caught per day, reported by the fisher. We grouped the records by time periods (1980s or earlier, 1990s, 2000s) and fishing gear used. We used a GLM to standardize the reported CPUE and test for any changes in CPUE over different time periods.

\section{RESULTS}

\section{Catches and CPUE}

Total landings of Nassau grouper in the Bahamas declined gradually from 1994 to 2009, according to official government figures (Fig. 1). As reported by Ehrhardt \& Deleveaux (2007, p. 19)

[a] survey of local fish consumption in the Bahamas during 2003 (Talaue-McManus and Hazell, personal communication) estimated that the official grouper statistics were underestimated by $94 \% \ldots$

Therefore, we corrected for the reported landings by an assumed under-estimation of $94 \%$. Overall, Bahamas' Nassau grouper catches declined from around $1300 \mathrm{t}$ in 1994 to $400 \mathrm{t}$ in 2009 (Fig. 1a), representing a $70 \%$ decline during this period. Moreover, the proportion of Nassau grouper in the total fishery
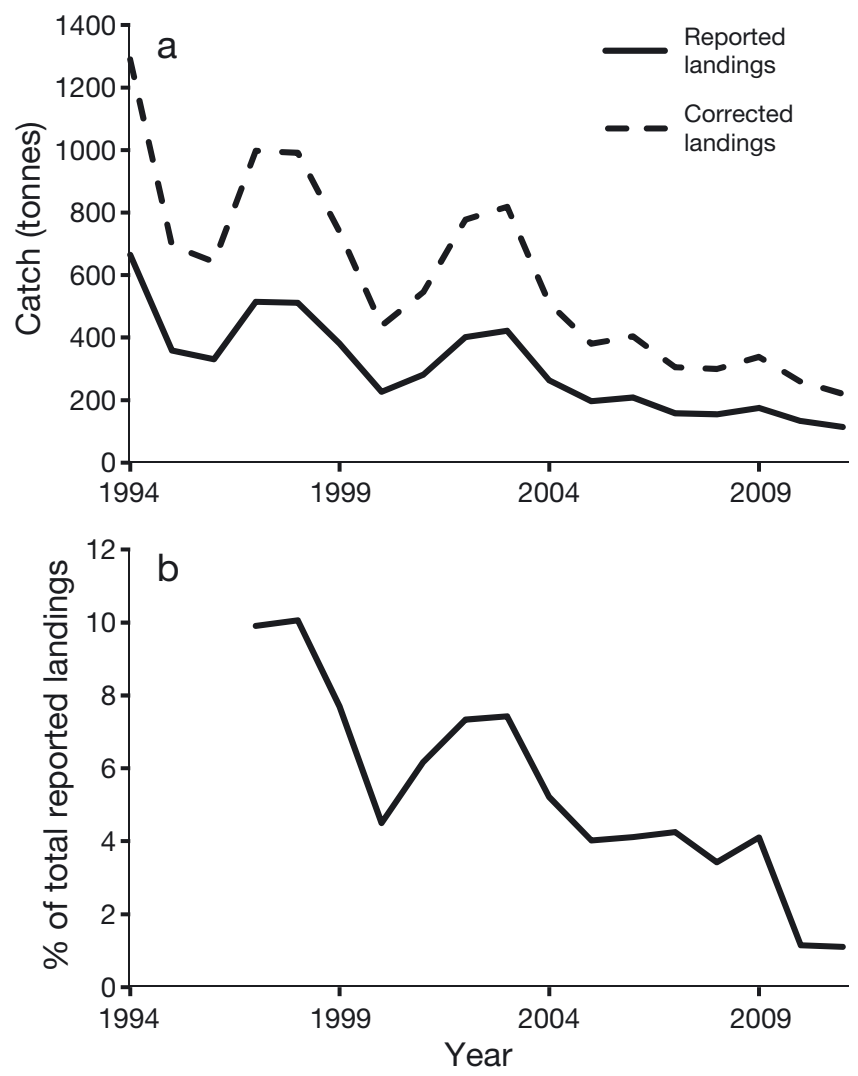

Fig. 1. Epinephelus striatus. Reported landings (in t) of Nassau grouper in the Bahamas from 1994 to 2009 (a) as compiled by the Bahamas Department of Marine Resources (solid line) and corrected for under-reporting of fisheries landings by a factor of $94 \%$ (broken line, Ehrhardt \& Deleveaux 2007), (b) expressed as a percentage of the total reported landings for all fishes and invertebrates. The ban on fishing of spawning aggregations began in High Cay in December 1998 and was later extended to Long Island. There were no closures in 2001 to 2004 but a 2 mo closure, later extended to $3 \mathrm{mo}$, started in 2005

landings in the Bahamas also declined from 10 to $<4 \%$ during this period, suggesting that the decline in landings was not mirrored in other exploited taxa (Fig. 1b). Various reasons may explain the decline in Nassau grouper landings, including decline in stock abundance, reduction in fishing effort, and/or an increase in the level of under-reporting of fishery landings.

Analysis of the daily CPUE data from 1999 to 2004 suggested that Year is not a significant factor explaining the variation in CPUE (see the supplement). Part of the variation in CPUE can be explained by fishing gear type (higher for spearfishing, fish-trapping, and unspecified gear), fishing ground (higher in New Province, Nassau), and season (lower in February, March, and July to September). 
Mortality, selectivity, and abundance in 1998 to 2001

Re-analysis of the catch (landings)-at-length data suggests that fishing mortality and exploitation rates of the Bahamas' Nassau grouper population from 1998 to 2001 may be higher than previous estimates. Total mortality rates, estimated from the slope of the length-converted catch curves, were $0.45,0.42$, and $0.36 \mathrm{yr}^{-1}$ for the periods 1998/99, 1999/00, and 2000/ 01, respectively (Fig. 2). Based on the natural mortality rate of $0.18 \mathrm{yr}^{-1}$ used by Ehrhardt \& Deleveaux (2007), the fishing mortality rates were estimated to be $0.27,0.24$, and $0.18 \mathrm{yr}^{-1}$ while the exploitation rates $(U)$, calculated as $U=F / Z$, were $0.6,0.57$, and 0.50 , respectively. These are higher than the fishing mortality and exploitation rates estimated by Ehrhardt \& Deleveaux (2007) using the same set of data and methods, with their estimated $F$ and $U$ ranging from 0.06 to $0.11 \mathrm{yr}^{-1}$ and 0.25 to 0.38 , respectively. Estimates of $F$ and $U$ from the present study were used in VPA and the stock assessment model.

Based on length-based VPA, abundance of the Bahamas' Nassau grouper from 1998/99, 1999/00, and 2000/01 was estimated to be 72.6 million, 54.5 million, and 44.2 million fish, or 177400,134500 and $112000 \mathrm{t}$, respectively. Estimated recruits to the stock (assumed to be fish less than $40 \mathrm{~cm}$ ) were 20.3 million, 15.3 million, and 12.0 million. Abundance and recruitment appeared to be declining, although estimates for a period of $3 \mathrm{yr}$ could not be used to infer the longer-term trend. Because of the difference in estimated fishing mortality rates, abundance and biomass estimated from this study are higher than the original estimates of Ehrhardt \& Deleveaux (2007): 35 to 52 million fish or 116000 to $131000 \mathrm{t}$, respectively). Selectivity of the Bahamas' Nassau grouper fisheries was estimated to be dome-shaped. The average fishery selectivity between 1998 and 2001 , representing the proportion of the population vulnerable to fishing mortality, was estimated to be dome-shaped with sizes-at- $50 \%$ capture of about 59 and $76 \mathrm{~cm}$, and size-at-100\% capture of $64 \mathrm{~cm}$. The estimated selectivity was applied to the population dynamic model to simulate responses of the Nassau grouper population to different levels of fishing mortality.

\section{Population dynamic modeling}

The model outputs indicate that, if fishing effort for the Bahamas' Nassau grouper has not been reduced from the 1998 to 2001 level (the data analyzed come
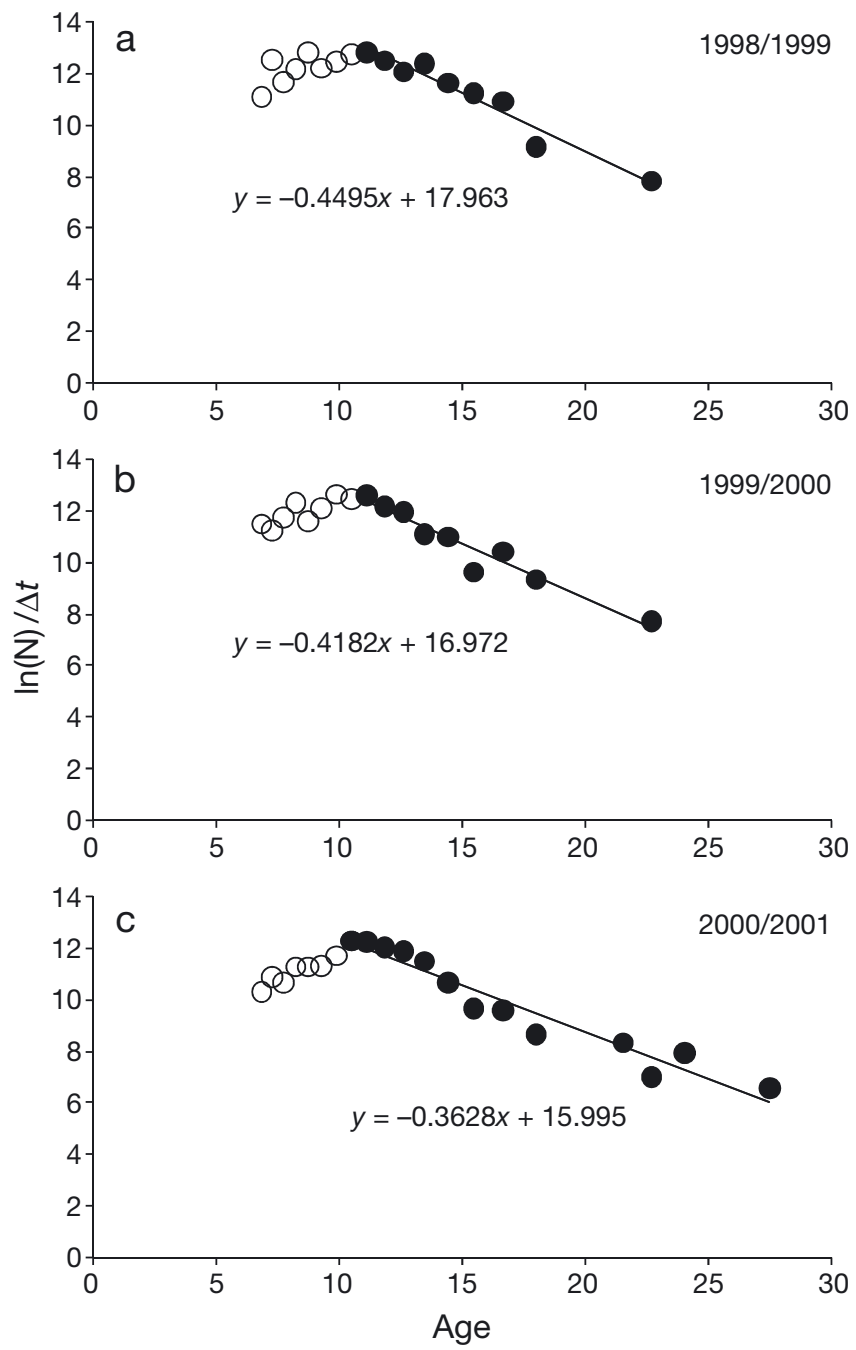

Fig. 2. Epinephelus striatus. Analysis of landings-at-length data using the length-based catch curve for the periods (a) 1998 to 1999, (b) 1999 to 2000, (c) 2000 to 2001. Black dots represent the length/age after which individuals were fully vulnerable to fishing gear and were used in the linear regressions; open dots are data points excluded from the analysis. Total mortality $(Z)$ of the populations was estimated from the slope of the fitted line. $\mathrm{N}$ : number of fish; $\Delta t$ : as defined in Eq. (2)

from this period), the stocks are likely to be overexploited (Fig. S1 in the supplement at www.int-res. com/articles/suppl/n020p027_supp.pdf). Assuming that the closure of the spawning aggregation season is perfectly implemented and enforced, the median value of $F_{\mathrm{SPR}=35 \%}$ on non-spawning fish would be $50 \%$ of the fishing mortality of the 1998 to 2001 level (Fig. S1). The 5 and $95 \%$ confidence limits are estimated to be less than $20 \%$ and more than $100 \%$ of the fishing mortality at the 1998 to 2001 level, respectively. In other words, if (1) fishing mortality rates of non-spawning fish are maintained at the 1998 to 
2001 level and (2) fishing on spawning aggregations is negligible, the median spawning potential (spawner biomass relative to the unexploited level) is expected to be around $25 \%$ (5 and $95 \%$ CI of 20 and $30 \%$, respectively). This is significantly below the reference limit of $35 \%$ of spawning potential, meaning that there is a high chance of recruitment overfishing because of the low spawning stock biomass. We considered the possibility that fishing mortality in the 1998 to 2001 period was over-estimated because of the uncertainty in the catch-curve analysis. Testing the sensitivity of the results to a lower fishing mortality rate $(50 \%$ of the estimated rate from the catchcurve analysis), spawning potential may be a median of around $35 \%$ (5 and $95 \%$ CI of 20 to $40 \%$ ) relative to the unexploited level. Under either scenario, and given poor enforcement, it is clear that any increases in the fishing mortality rate (relative to the average 1998 to 2001 level), either in non-spawning or in spawning periods, may lead to alarmingly low spawning potential.

Any fishing effort on spawning aggregations, through poaching or opening of the fishing closure, may lead to further reduction in spawning potential. For instance, if the fishing closure on spawning aggregations or during the spawning season were to be completely lifted, and if both the non-spawning period and spawning periods were subject to the baseline (1998 to 2001) fishing mortality rate, the median spawning potential is expected to be reduced to below $20 \%$ of the unexploited level, with significant chances of elimination of spawning biomass (probability $>5 \%$, Fig. S1).

The median fishing mortality rate that achieves long-term MSY was estimated to be approximately $80 \%$ of the baseline (1998 to 2001) level, with lower and upper $5 \%$ confidence limits of 40 and $90 \%$ of the baseline level, respectively (Fig. S2 in the supplement at www.int-res.com/articles/suppl/n020p027_ supp.pdf). The large confidence intervals mean that there is a significant chance that the population may now be over-exploited if fishing mortality remains at the 1998 to 2001 level (>5\%). The fishery may be considered fully exploited if we conservatively assume that fishing mortality rate is $50 \%$ the estimated value from the catch-curve analysis.

\section{Bioeconomic analysis}

We found that fishing mortality should be reduced from the 1998 to 2001 level to achieve MER (Fig. S3 in the supplement at www.int-res.com/articles/suppl/ n020p027_supp.pdf). Based on the supplementary interviews with 32 fishers, the estimated average price reported by the study is US\$ $5.17 \mathrm{~kg}^{-1}$ of catch. Variable and fixed costs from the Global Ocean Economic project are $\$ 0.83$ and $\$ 0.06 \mathrm{~kg}^{-1}$ of catch, respectively. Under the scenario where the spawning population of Nassau grouper is fully protected, the median $F_{\text {MER }}$ was calculated to be approximately $60 \%$ of the baseline (1998 to 2001) level. The most profitable scenario appears to be halving the nonspawning fisheries while fishing modestly on the spawning aggregations. However, such a strategy would result in large depletion of spawning potential to less than $30 \%$ of the unexploited level and thus would be ecologically undesirable. It would also be very difficult to control/enforce.

\section{Analysis of interview data}

From 2009 to 2011, 280 Bahamas' fishers were interviewed during a project conducted by the Bahamas' Department of Marine Resources. The age of these fishers ranged from $20+$ to over 70 yr old, with the majority being in their 30 s to 60 s. Most had at least $15 \mathrm{yr}$ of experience fishing in the Bahamas, and most were engaged in fishing full-time with around 60 being part-time, subsistence, or occasional fishers. For most of the interviewed fishers, however, fishing is typically their main livelihood, contributing over $75 \%$ of the income. Fishermen were interviewed from areas throughout the Bahamas north of Crooked Island. Catches of Nassau grouper make up 5 to $50 \%$ of their income, both before and after the spawning aggregation closure in 1998, although its contribution to fishers' incomes appears to have reduced after the closure.

The interviewed fishers were asked about their perspective on the trend of the Bahamas' Nassau grouper landings in the 1990s prior to the spawning aggregation closure. About $41 \%$ of fishers thought that the fishery during the non-spawning period was stable, while more fishers thought that landings decreased rather than increased or remained stable during the spawning period (Fig. 3). The perceived trends during and outside of the spawning aggregation periods were significantly different $\left(\chi^{2}\right.$ test $<0.01$ ). Overall, the average number of fishing days reported by the interviewed fishers increased from $4 \mathrm{~d} \mathrm{yr}^{-1}$ in the $1980 \mathrm{~s}$ to $6.5 \mathrm{~d} \mathrm{yr}^{-1}$ in the 2000s. Although the increase was not statistically significant, it does suggest that increasing catches might have been attributable to increased effort. 
The interviewed fishers reported the largest catch of Nassau grouper on a single trip from fishing a spawning aggregation that they could remember, with the results suggesting that the maximum catch

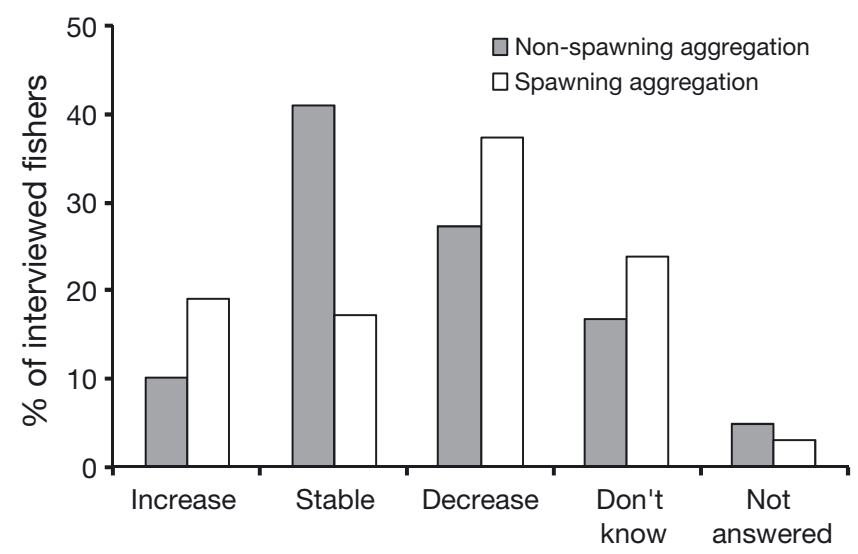

Fig. 3. Epinephelus striatus. Perceptions of interviewed fishers on the trends of landings in the Bahamas during the non-spawning period (grey bars) and spawning aggregation period (open bars) in the 1990s prior to the spawning aggregation closure
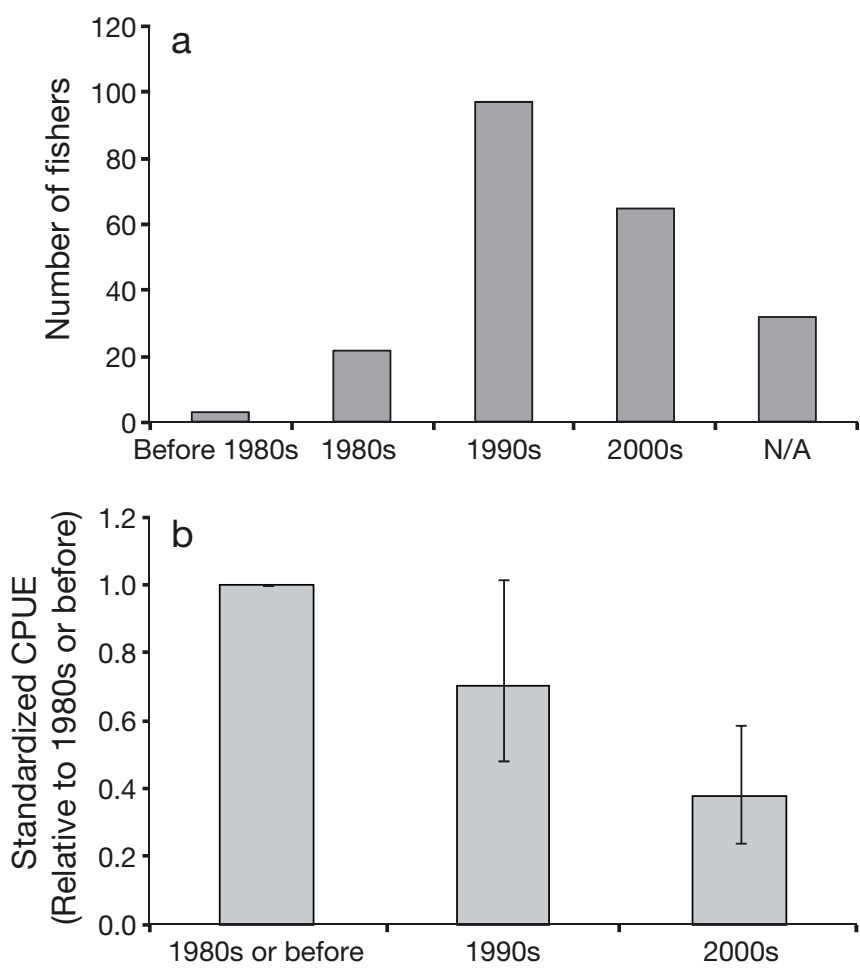

Fig. 4. Epinephelus striatus. Reported experiences of interviewed fishers on fishing of spawning aggregations: (a) the last time (year) when the interviewees fished on an aggregation, and (b) the generalized linear model-estimated standardized maximum catch per unit effort (CPUE) of the largest catch from an aggregation (relative to the 1980s or before) reported by the fishers in the Bahamas over their career. Error bars are SE was perceived to have declined in recent years (Fig. 4). Most of the fishers recalled their largest catches from spawning aggregations in the 1990s and 2000s (Fig. 4a). However, after accounting for the reported fishing effort (number of days) used to obtain the catch, by converting the recalled catch into CPUE (catch per day fishing) and standardized across fishing gear types through a GLM, CPUE appeared be on a declining trend from the 1980s, or before, to the 2000s. Particularly, the standardized CPUEs in the 2000s were significantly lower (by an average of about $40 \%$ ) than the reported CPUEs in the 1980 s or earlier (Fig. 4b). Thus, although the largest catches occurred in more recent years, this was achieved through higher fishing effort. The interviewed fishers reported some differences in catch during non-spawning periods before and after the spawning aggregation closure. Fishers had diverse views regarding their present Nassau grouper catch during non-spawning periods compared to before the closure (Fig. 5).

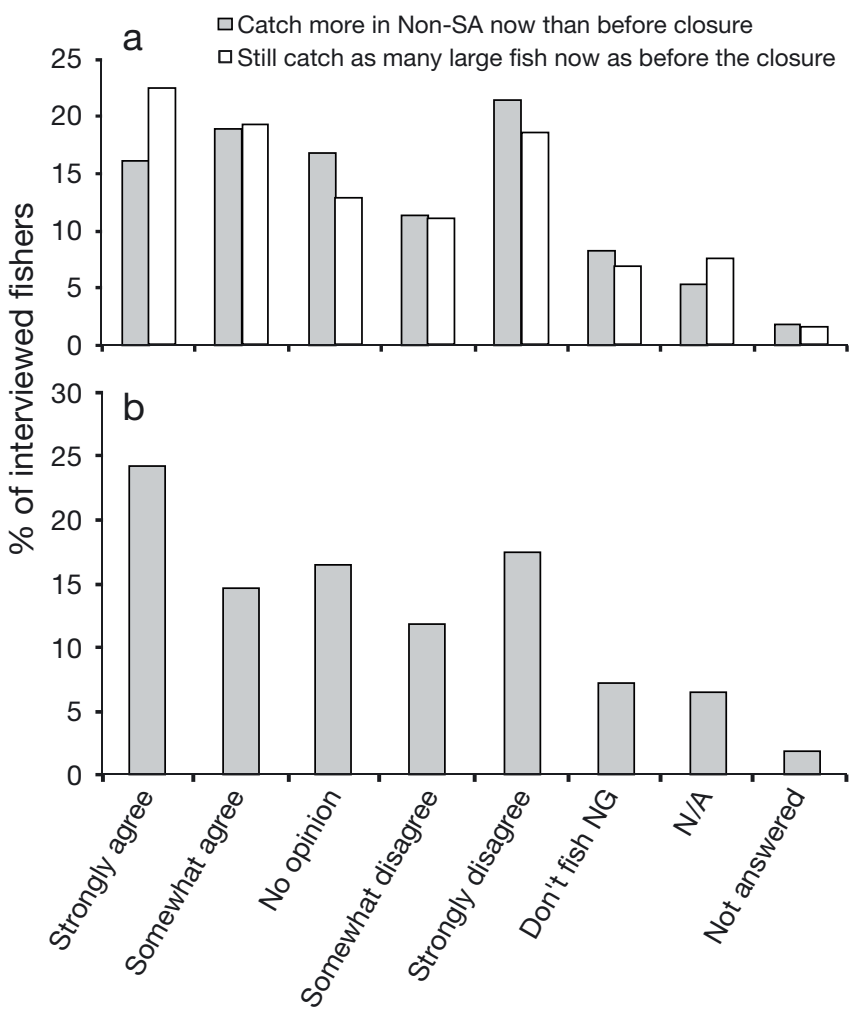

Fig. 5. Epinephelus striatus. Responses of interviewed fishers to the statement (a) 'I catch more Nassau grouper now during the non-spawning period than I did in the nonspawning period before the closures' (grey bars), 'I still catch as many large fish now as I did before the closures' (open bars), and (b) 'I catch more small fish than I did before the closures'. NG: Nassau grouper; N/A: not applicable 


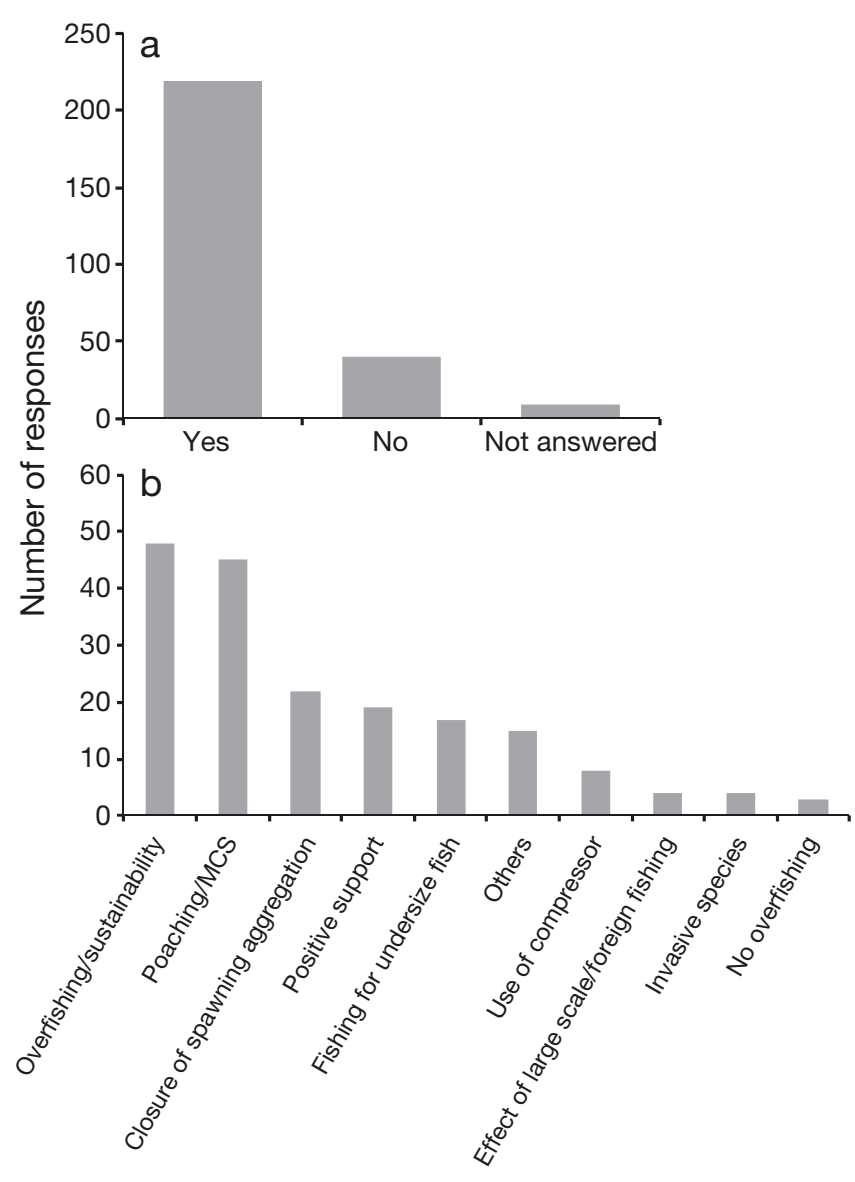

Fig. 6. Epinephelus striatus. Summary of views expressed by interviewed fishers when asked (a) whether they are concerned about the future of the Nassau grouper fisheries and (b) what their specific concerns are. Descriptions from the fishers were grouped into the categories given on the $x$-axis (MCS: Monitoring, Control and Surveillance). Views from a fisher may fall into more than 1 category

The majority of the fishers (82\%) had concerns about the future of the Bahamas' Nassau grouper fishery (Fig. 6). The most common concerns were with overfishing of the population and the long-term sustainability of the Nassau grouper fishery ( $\mathrm{N}=48$ responses), and the issues of poaching and 'monitoring, control, and surveillance' (MCS) for the spawning aggregation closure $(\mathrm{N}=45)$. There was some concern about the continued closure of the spawning aggregation $(\mathrm{N}=22)$. Some thought that it would affect their livelihood, while some thought it should be modified to increase its effectiveness. Another concern was the increased exploitation of small-sized fish ( $\mathrm{N}=17$ ). Some fishers expressed concerns about fishers using compressors to fish, the effects of largescale foreign fishing, and invasive species (specifically lionfish). Nineteen interviewed fishers expressed support of the closure.

\section{DISCUSSION}

This study suggests that the Nassau grouper population in the Bahamas may be over-exploited. First, the Bahamas' Nassau grouper landings have been declining steadily since the 1990s, while total fishery landings did not decline to the same extent, indicating a differential decline in the Nassau grouper. This decline occurred before the implementation of the spawning aggregation closure. The declining landings, particularly from spawning aggregations prior to the closure, were also reflected in the fisher interviews. The Nassau grouper population was likely to be fully exploited, and possibly over-exploited, in 1998 to 2001, given that the estimated fishing mortality rates were higher than the fishing mortality reference points reported by Ehrhardt \& Deleveaux (2007) $\left(F_{\max }=0.15 \mathrm{yr}^{-1}\right.$ and $\left.F_{0.1}=0.14 \mathrm{yr}^{-1}\right)$.

An alternative explanation for the decline in landings since the 1990s is a reduction in fishing effort and an underexploited stock. However, there was no indication that fishing effort during the non-spawning period has declined substantially over the period examined; indeed, the opposite is suggested. Particularly, most of the fishers engage in multi-species fisheries, and Nassau grouper is only one of the many species they catch. There was no apparent reduction in landings of other species, suggesting that the overall fishing effort did not decline. Also, although bans on fishing during spawning and on selected spawning aggregations have been implemented since the late 1990s, which may have reduced overall Nassau grouper catch, the decline in catch started before the implementation of these measures. At the same time, a considerable level of poaching was reported by the interviewed fishers. Moreover, fishers also reported a reduction in mean body size of the catch; this is often a sign of over-exploitation of the population. Other alternative explanations for the decline in landings and CPUE may include invasive species, climate change, and/or diseases/parasites that led to unaccounted mortalities or reduction in population abundance and productivity. However, there was no evidence to support these alternative explanations.

If fishing effort has remained similar to that in 1998 to 2001 or has since increased, spawning potential of the Nassau grouper population is likely now reduced to a level that would have resulted in recruitment overfishing. This is indicated by outputs from the population dynamic model that suggest that the population is likely to be fully to over-exploited, with dangerously low spawning potential, assuming the 1998 to 2001 fishing mortality level. Particularly, esti- 
mates of $F_{\mathrm{MSY}}$ are based on the assumption that the spawning aggregation closure was perfectly implemented and enforced and that fishing mortality rate on spawning aggregations is negligible. However, this assumption is not valid, as problems with enforcing the seasonal closure and poaching were clearly identified by the fishers who reported that fishing occurred on the spawning aggregation(s) after the closure. The population dynamic model suggests that any level of fishing on spawning aggregations in addition to the existing level of fishing on nonspawning stocks would greatly increase the extent of over-exploitation and risk of recruitment failure (indicated by low spawning potential). Moreover, the maximum number of Nassau grouper caught per day from spawning aggregations reported by the interviewed fishers declined significantly over the 3 decades immediately prior to the closure. All of these observations are fully consistent with the suggestion that the Bahamas' Nassau grouper population has been over-exploited. Given that continued fishing on spawning aggregations is likely (see results from fisher interviews), fishing effort in the non-spawning period needs to be substantially lowered from the baseline level. Otherwise, the Nassau grouper population will continue to be overfished.

A precautionary approach to managing the Bahamas' Nassau grouper is to maintain the spawning aggregation period closure, and improve the MCS of the fishery, while, in addition, fishing effort during non-spawning periods should be reduced from the 1998 to 2001 level. Nassau grouper populations have been widely overfished, as judged by the disappearance of spawning aggregations and vanishing landings in most of the species' geographic range. Our assessment further suggests that the population in the Bahamas may have a high risk of recruitment failure and serious over-exploitation, particularly if the fishing closure during the spawning period were to be lifted, or poaching during the closure were to occur. Also, we did not account for the scenarios of fishing gear changes, e.g. changes in gear selectivity to include smaller fishes or the use of compressors. Accounting for this factor may reduce the optimal fishing mortality for the Nassau grouper population. These other possible scenarios highlight the risk and high susceptibility of the species to overexploitation. The species is listed as 'Endangered' on the IUCN Red List of Threatened Species due the above concerns. It is a priority to ensure that the fishing closure is effectively enforced.

It is clear that fishing effort during the non-spawning period should be maintained below the 1998 to
2001 level. Reducing fishing effort level from that level will also improve the economic performance (rent) of these fisheries. Thus, the reduction in fishing mortality $F$ appears to be a 'win-win' strategy to achieve favorable ecological and economic objectives in the long term. In addition, the use of new technology (e.g. compressor) or modification of fishing gear (e.g. introduction of gear that targets smaller fish), both expressed as concerns by interviewed fishers, should be monitored and taken into account when deciding management measures. The introduction of compressors, in particular, should be a major cause for concern, given its contribution to overfishing in many parts of the Pacific and as a cause of decompression sickness in fishers (Gillett \& Moy 2006). Other potential and emerging threats, such as species invasion (e.g. lionfish; Albins \& Hixon 2008) and climate change (Cheung et al. 2009), should be monitored and assessed.

Although data for the current assessment are limited, the use of multiple data sources and approaches, as in the present study, substantially increases the robustness of the assessment. Formal data for fishery stock assessment are limited, with catch-at-size data only available for the 1998 to 2001 period, while detailed fishing effort data are not available. Also, we did not consider the spatial dynamics of the population and fisheries which may have implications for the interpretation of the data. For example, fishing may have sequentially exploited the Nassau grouper population. Thus, fish catches may remain stable although total population size has decreased (Sadovy \& Domeier 2005). Thus our assessment on the reported CPUE over time may underestimate the population decline. We attempted to address some of the uncertainties of the input parameters used in the assessment using a Monte Carlo approach. Accounting for these uncertainties, the recommendation that spawning aggregations should be more effectively protected and that fishing effort should not be increased from the 1998 to 2001 level appears robust. Also, we supplemented formal assessment with data collected from sporadic surveys and recent fisher interviews. Results obtained from assessing the various data sources and types of data appear to corroborate each other. This suggests some robustness in our analysis.

Data necessary to assess the current status of the population should be collected regularly to re-assess the status of the species and compare it with earlier assessments. These data should include at least (1) total catch and landings (by fishing gear); (2) fishing effort (by location); (3) catchability and its changes 
over time/space; (4) catch-at-size data (preferably fishery-independent); (5) CPUE and/or abundance data (preferably fishery-independent); and (6) price and fishing costs (by fishing gear types).

Trade-offs are likely to exist between the move to more sustainable management of the Bahamas' Nassau grouper population and the livelihood of the fishers in the short term. From the interview survey, some fishers who were concerned about the closure of the spawning aggregation felt that the closure was negatively affecting their income and livelihood. However, our bioeconomic analysis suggests that the spawning aggregation protection would increase the long-term economic rent of the Bahamas's Nassau grouper fishery. On the other hand, a large proportion of fishers also expressed their concerns about overfishing, Nassau grouper depletion, and sustainability of the fishery. If over-exploitation is the cause of the declining catch and CPUE in recent decades, rebuilding of the over-exploited population would actually improve the economic performance of the fishery over the intermediate to long term, and hence benefit the income and livelihood of the fishers. If the present situation is not addressed, however, overexploitation could spiral down to the loss of revenue through ongoing declines in landings and abundance, with the possibility of collapse of the fishery and unknown prospects for recovery. The latter has happened in other Nassau grouper fisheries in the region (Sadovy \& Eklund 1999, Sala et al. 2001).

\section{CONCLUSIONS}

This study assessed the status and trends in the Bahamas' Nassau grouper population and fishery. The results suggest that the population is likely to be fully to over-exploited, although this needs to be validated when more fishery and population data are collected and analyzed. A number of international conventions including the United Nations Convention on the Law of the Seas and the Convention on Biological Diversity stipulate that the signatory countries, including the Bahamas, should ensure sustainable management (generally defined by the MSY in these conventions) of their fisheries resources, further highlighting the need to ensure effective management of the Bahamas' Nassau grouper fisheries, while the FAO Code of Conduct for Sustainable Fisheries outlines a voluntary set of guidelines for sustainable management, including the protection of spawning grounds. Data necessary to assess the current status of the population should be collected regularly to re-assess the status of the species and compare it with earlier assessments. These data should include at least the 6 points mentioned in the 'Discussion' above. All results indicate that the fishery appears to be under decline, with threats to spawning biomass. Given that the Nassau grouper is an aggregating species, attention must also be paid to the possibility that severely reduced aggregation sizes could compromise reproduction, as, for example in the case of the Allee effect (Sadovy de Mitcheson \& Erisman 2012). A precautionary approach to managing the Bahamas' Nassau grouper is, at the very least, to maintain the spawning aggregation period closure, and to improve the MCS.

Moreover, fishing effort during the non-spawning period should be reduced from the 1998 to 2001 level and attention paid to catches of immature fish and compressor-based fishing. Such measures would address the principal concerns expressed by fishers about the Nassau grouper fishery in relation to the sustainability of the fishery and the issues of poaching and enforcement of fishery management measures. Although decline in $F$ (fishing mortality, proportional to fishing effort) may affect the short-term economic benefits, the fishery would perform better economically over the long term. The social implications of these management policies (e.g. in terms of livelihood and equality of access to resources by communities) were not assessed in this study and should be evaluated in future studies.

Acknowledgements. We are grateful to the Bahamas' Department of Marine Resources for providing us with data from the fisher survey. W.W.L.C. acknowledges funding from the National Geographic Society. We thank N. Ehrhardt for sharing the fishery data with us, and V. Lam for providing us with the fishing cost data. This study and the fisher interviews were fully funded by the Caribbean Fishery Management Council.

\section{LITERATURE CITED}

Albins MA, Hixon MA (2008) Invasive Indo-Pacific lionfish Pterois volitans reduce recruitment of Atlantic coral-reef fishes. Mar Ecol Prog Ser 367:233-238

Bay LK, Caley MJ, Crozier RH (2008) Meta-population structure in a coral reef fish demonstrated by genetic data on patterns of migration, extinction and re-colonisation. BMC Evol Biol 8:248

Cheung WWL, Pitcher TJ (2008) Evaluating the status of exploited taxa in the northern South China Sea using intrinsic vulnerability and spatially explicit catch-perunit-effort data. Fish Res 92:28-40

Cheung WWL, Pitcher TJ, Pauly D (2005) A fuzzy logic expert system to estimate intrinsic extinction vulnerabil- 
ities of marine fishes to fishing. Biol Conserv 124:97-111 Cheung WWL, Lam VWY, Sarmiento JL, Kearney K, Watson R, Pauly D (2009) Projecting global marine biodiversity impacts under climate change scenarios. Fish Fish 10: 235-251

Cornish AS, Eklund AM (2003) Epinephelus striatus. In: 2010 IUCN Red List of Threatened Species Book Version 2010.4. Available at www.iucnredlist.org/details/7862/0 (accessed 1 Feb 2011)

Ehrhardt NM, Deleveaux VKW (2007) The Bahamas' Nassau grouper (Epinephelus striatus) fishery - two assessment methods applied to a data-deficient coastal population. Fish Res 87:17-27

Froese R, Pauly D (eds) (2011) FishBase. www.fishbase.org Gillett R, Moy W (2006) Spearfishing in the Pacific Islands. Current status and management issues. Information Paper 7, FAO, Rome. www.spc.int/DigitalLibrary/Doc/ FAME/Meetings/HOF/5/IP7.pdf

Hilborn R, Walters CJ (1992) Quantitative fisheries stock assessment: choice, dynamics and uncertainty. Chapman \& Hall, London

Jackson JBC, Kirby MX, Berger WH, Bjorndal KA and others (2001) Historical overfishing and the recent collapse of coastal ecosystems. Science 293:629-637

Jones R (1984) Assessing the effects of changes in exploitation pattern using length composition data. FAO Fish Tech Pap 256. FAO, Rome

Lam VWY, Sumaila UR, Dyck A, Pauly D, Watson R (2011) Construction and first applications of a global cost of fishing database. ICES J Mar Sci 68:1996-2004

Pauly D (1995) Anecdotes and the shifting baseline syndrome. Trends Ecol Evol 10:430

Reynolds JD, Dulvy NK, Goodwin NB, Hutchings JA (2005) Biology of extinction risk in marine fishes. Proc $\mathrm{R}$ Soc Lond B Biol Sci 272:2337-2344

Editorial responsibility: Cornelius Hammer, Rostock, Germany
Sadovy Y, Colin PL (1995) Sexual development and sexuality in the Nassau grouper. J Fish Biol 46:961-976

Sadovy Y, Domeier M (2005) Are aggregation-fisheries sustainable? Reef fish fisheries as a case study. Coral Reefs 24:254-262

Sadovy Y, Eklund AM (1999) Synopsis of biological data on the Nassau grouper, Epinephelus striatus (Bloch, 1792), and the Jewfish, E. itajara (Lichtenstein, 1822). NOAA Tech Rep NMFS 146. FAO Fisheries Synopsis 157. US Department of Commerce, Seattle, WA

Sadovy Y, Punt AE, Cheung WL, Vasconcellos M, Suharti S, Mapstone BD (2007) Stock assessment approach for the Napoleon fish, Cheilinus undulatus, in Indonesia. A tool for quota setting for data-poor fisheries under CITES Appendix II Non-Detriment Finding requirements. FAO Fisheries Circular No. 1023. FAO, Rome

Sadovy de Mitcheson Y, Erisman B (2012) Fishery and biological implications of fishing spawning aggregations, and the social and economic importance of aggregating fishes. In: Sadovy de Mitcheson Y, Colin PL (eds) Reef fish spawning aggregations: biology, research and management. Fish Fish Ser Vol 35. Springer, London, p 225-284

Sadovy de Mitcheson Y, Cornish A, Domeier M, Colin PL, Russell M, Lindeman KC (2008) A global baseline for spawning aggregations of reef fishes. Conserv Biol 22: 1233-1244

Sáenz-Arroyo A, Roberts C, Torre J, Cariño-Olvera M, Enríquez-Andrade R (2005) Rapidly shifting environmental baselines among fishers of the Gulf of California. Proc R Soc Lond B Biol Sci 272:1957-1962

Sala E, Ballesteros E, Starr RM (2001) Rapid decline of Nassau grouper spawning aggregations in Belize: fishery management and conservation needs. Fisheries 26: 23-30

Submitted: June 7, 2012; Accepted: October 15, 2012 Proofs received from author(s): January 6, 2013 